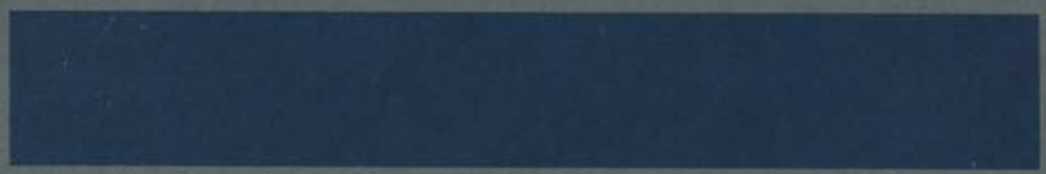

\title{
IN-PHANTOM DOSIMETRY OF PLUTONIUM-238 HEAT SOURCES IN RELATION TO CIRCULATORY SUPPORT SYSTEMS
}

\section{F. T. Cross and J. C. Sheppard}

September 1970

\section{AEC RESEARCH \& DEVELOPMENT REPORT}




\section{LEGAL NOTICE}

This report was prepared as an account of work sponsored by the United States Government. Neither the United States nor the United States Atomic Energy Commission, nor any of their employees, nor any of their contractors, subcontractors, or their employees, makes any warranty, express or implied, or assumes any legal liability or responsibility for the accuracy, completeness or usefulness of any information, apparatus, product or process disclosed, or represents that its use would not infringe privately owned rights.

\section{PACIFIC NORTHWEST LABORATORY}

RICHLAÑD, WASHINGTON

operated by

BATTELLE MEMORIAL INSTITUTE

for the

UNITED STATES ATOMIC ENERGY COMMISSION UNDER CONTRACT AT(45-1)-1830 
BNWL -1489

UC-41, Health and Safety

\section{IN - PHANTOM DOS IMETRY \\ DF PLUTONIUM-238 HEAT SOURCES \\ IN RELATION TO CIRCULATORY \\ SUPPORT SYSTEMS}

By

F. T. Cross

Radiological Sciences Department

Environmental and Life Sciences Division

and

$$
\text { J. C. Sheppard }
$$

Chemical Technology Department Chemistry and Metallurgy Division
FHRST UNRESTRICTED DISTRIBUTION MADE

\section{SEP1:'70}

September 1970

BATTELLE MEMORIAL INSTITUTE 
Printed in the United States of America Available from

Clearinghouse for Federal Scientific and Technical Information National Bureau of Standards, U.S. Department of Commerce Springfield, Virginia 22151

Price: Printed Copy \$3.00; Microfiche $\$ 0.65$ 


\author{
IN-PHANTOM DOSIMETRY \\ OF PLUTONIUM-238 HEAT SOURCES \\ IN RELATION TO CIRCULATORY \\ SUPPORT SYSTEMS \\ F. T. Cross and J. C. Sheppard
}

\begin{abstract}
The dose rates from an implanted ${ }^{238} \mathrm{Pu}$ heat source have been measured and calculated. The source material was medical grade plutonium of nominal $30 \mathrm{~W}$ strength. The tissue-equivalent phantoms were both a large homogeneous right-circular cylinder and a Remab phantom. Calculated dose rates agreed to within $20 \%$ with measured values except for positions very close to the source. The reasons for discrepancies greater than this are stated in the text and, in brief, are thought mainly to arise from the uncertainties in the photon emission rate and the use of dosimeters too large for neutron measurements close to the source. In general, the agreement of the measured and calculated values is good, at least in the regions where the photons and neutrons make their greatest dose contribution for a source enclosed in a circulatory support system.
\end{abstract}




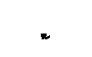

. 


\section{TABLE OF CONTENTS}

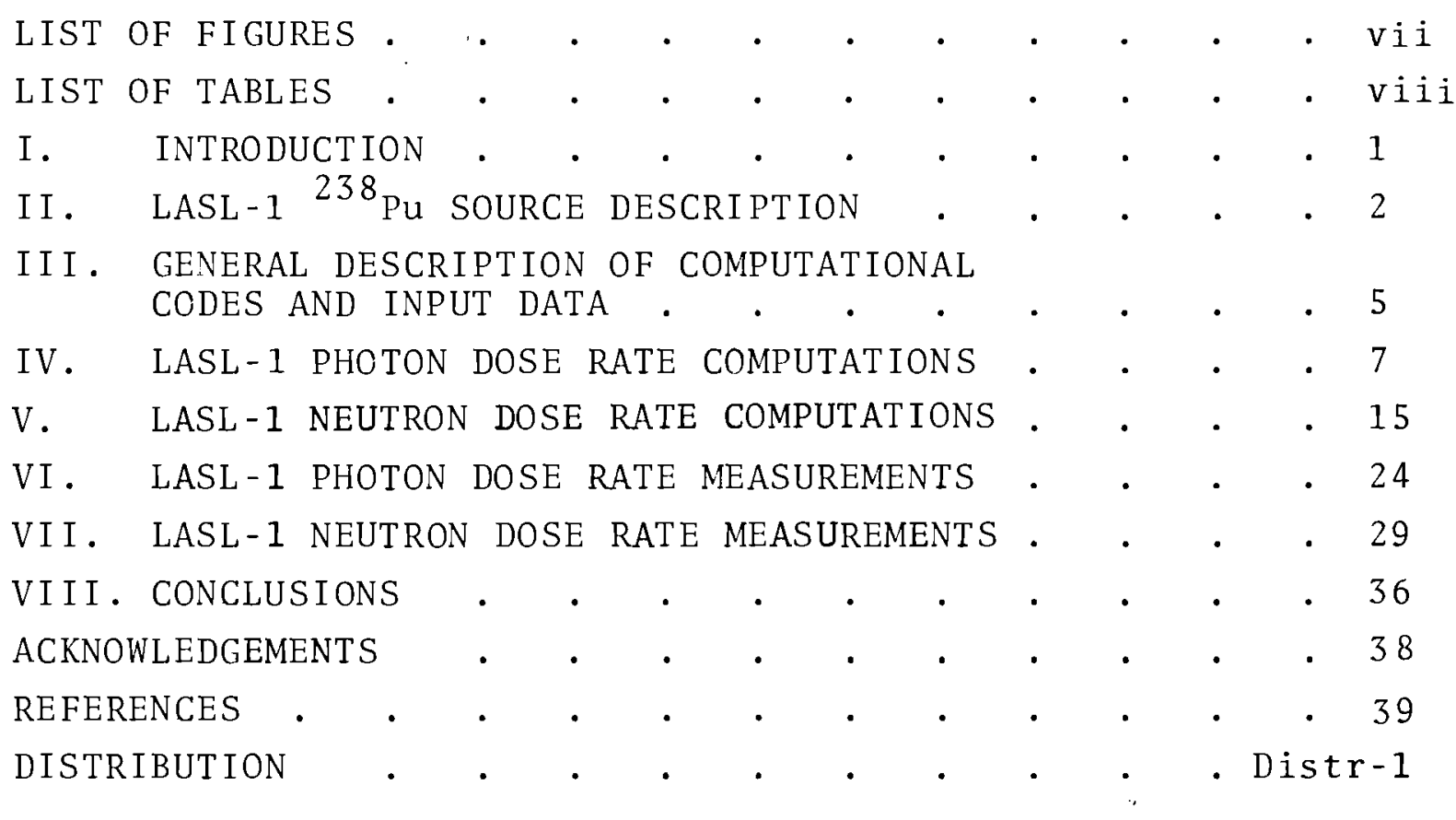




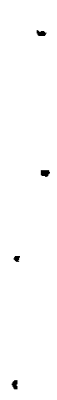




\section{LIST OF FIGURES}

1 Schematics of LASL-1 and Heat Exchanger

2 Comparison of LASL-1 Photon Measurements and Computations, Radially

3 Comparison of LASL-1 Photon Measurements and Computations, Axially

4 LASL-1 Photon Dose Rates as a Function of Time

5 Monte Carlo Calculations for Fission Spectra Neutrons in a Cylindrical Tissue Phantom

6 Neutron Dose Rates in Tissue for a $1.0 \mu \mathrm{g}$ $252 \mathrm{Cf}$ Source

7 Comparison of LASL-1 Neutron Measurements and Computations, Radially

8 Comparison of LASL-1 Neutron Measurements and Computations, Axially

9 LASL-1 In-Phantom Photon Dose Rates, Radial Planes

10 LASL-1 In-Phantom Photon Dose Rates, Axial Planes

11 Total $(n+\gamma)$ Dose-Rates in mrads/hr on Surface of Remab Phantom

12 Total $(n+\gamma)$ Dose-Rates in mrads/hr in Bisecting Radial Plane of Source

13 Total $(n+\gamma)$ Dose-Rates in mrads/hr Along Central Axis of Remab Phantom 
BNWL - 1489

\section{LIST OF TABLES}

1 Properties and Composition of LASL-1

2 Material Thicknesses from LASL-1 Center

2

3 Energies and Intensities for Photons Assigned to $238 \mathrm{Pu}$ Alpha Decay

4 LASL-1 In-Phantom Photon Dose Rates (mrads/hr $\pm 15 \%$ )

5 LASL-1 In-Phantom Neutron Dose Rates (mrads/hr $\pm 20 \%$ ) 


\author{
IN-PHANTOM DOS IMETRY \\ OF PLUTONIUM-238 HEAT SOURCES \\ IN RELATION TO CIRCULATORY \\ SUPPORT SYSTEMS \\ F. T. Cross and J. C. Sheppard
}

\title{
I. INTRODUCTION
}

This is the second in a series of reports on the in-phantom dosimetry of radioisotopic heat sources for circulatory support systems. The first, published in 1969, (1) presented the protocols for the program and the computations and measurements of the dose rates for implanted ${ }^{147} \mathrm{Pm}_{2} \mathrm{O}_{3}$ heat sources. This report presents the computations and measurements for an implanted metallic ${ }^{238} \mathrm{Pu}$ heat source.

The objective of the In-phantom Dosimetry Program at the AEC's Pacific Northwest Laboratory (Battelle-Northwest) is to determine the dose from radioisotopic heat sources suitable for use in circulatory support systems. This objective is accomplished by measuring the dose rates within and surrounding various tissue-equivalent phantoms. Part of the program is concerned with the prediction of the measured dose rates by the development or employment of computational codes. The computer codes are also used in parametric studies and for the prediction of the in-phantom dose rates from sources not available for measurement.

Future experimentation will establish the perturbation of prototypic heat source subsystems and source impurities on the tissue dose rates and will detail the doses absorbed by various organ systems. Some organ doses can be derived from the measurements on the encapsulated source, but the values are not necessarily representative of the doses when the source is encased in representative subsystems. 
BNWL - 1489

\section{LASL-1 ${ }^{238}$ PU SOURCE DESCRIPTION}

LASL- 1 was prepared for the AEC by the Los Alamos Scientific Laboratory and was on loan to Battelle-Northwest for the in-phantom dosimetry studies. The source properties and composition shown in Table 1 are mainly values supplied by LASL.

\section{TABLE: 1. Properties and Composition of LASL-1}

\begin{tabular}{|c|c|}
\hline $\begin{array}{l}\text { Wt of alloy, Pu-1 wt: Ga, g } \\
\text { Wt\% Ga by chemical analys is }\end{array}$ & $\begin{array}{r}66.50 \\
0.94\end{array}$ \\
\hline Wt of $\mathrm{Pu}, \mathrm{g}$ & 65.88 \\
\hline Power, W (assuming $0.456 \mathrm{~W} / \mathrm{g} \mathrm{Pu}$ ) & 30.00 \\
\hline Power, $W$ (BNW measurements $1 / 30 / 70)$ & $29.034 \pm 0.063(2 \sigma)$ \\
\hline Neutron emission rate, $\mathrm{n} / \mathrm{sec}-\mathrm{g} \mathrm{Pu}$ & 2535 \\
\hline I sotope & $\simeq \mathrm{Ci}$ in Mixture* \\
\hline $5.8 \times 10^{-5}$ & 0.02 \\
\hline 80.51 & 900 \\
\hline 16.10 & 0.65 \\
\hline $240_{\mathrm{Pu}}$ & 0.40 \\
\hline 0.529 & 40 \\
\hline 0.122 & 0.00032 \\
\hline
\end{tabular}

* For practical purposes, a reference date for this mixture is 11/1/68.

The source is of "medical" grade metal having been electrorefined to remove most of the lower atomic-number elements. This minimizes the contribution of $(\alpha, n)$ reactions and, in effect, the neutron emission rate is that of the spontaneous fission process alone. The metal is in the shape of a rightcircular cylinder 0.720 in. diam by 0.625 in. 1ong which has been alloyed with gallium to 1 wto for stabilization in the $\delta$-phase. The plutonium-gallium alloy was then cast into a 
15-mil thick right-circular cylinder of Ta-10 Wmetal so that the plutonium rests at one end of the cylinder. This cylinder was then encapsulated in a similar 15-mil thick cylinder so that the plutonium is centrally positioned with respect to the outer container. One void in the inner container has the same volume as the plutonium metal and communicates with the source. The void in the outer container does not communicate with the plutonium and merely preserves symmetry for dosimetry purposes. The voids initially contained helium and argon in an 8:1 ratio at $580 \mathrm{~mm}$ Hig pressure; the void in communication with the source was added as a safety measure to prevent helium gas (produced by alpha decays) from causing swelling or rupturing of the source. When in use, the source is placed within a 1/16-in. thick aluminum heat exchanger which uses water coolant to remove the heat. Figure 1 contains schematics of the ${ }^{238} \mathrm{Pu}$ source and heat exchanger. Table 2 includes the material thicknesses which were used as input data to the modified code QAD-P5A for dose calculations.

TABLE 2. Material Thicknesses from LASL-1 Center

$\begin{array}{clc}\text { Material } & \text { Axial Direction, } \mathrm{cm} & \text { Radia1 Direction, } \mathrm{cm} \\ \mathrm{Pu} & 0.795 & 0.914 \\ \text { "voids" } & 1.99 & 0.0191 \\ \mathrm{Ta} & 0.0762 & 0.0762 \\ \mathrm{~A} 1 & 0.159 & 0.159\end{array}$

Tissue

Variable

Variable 


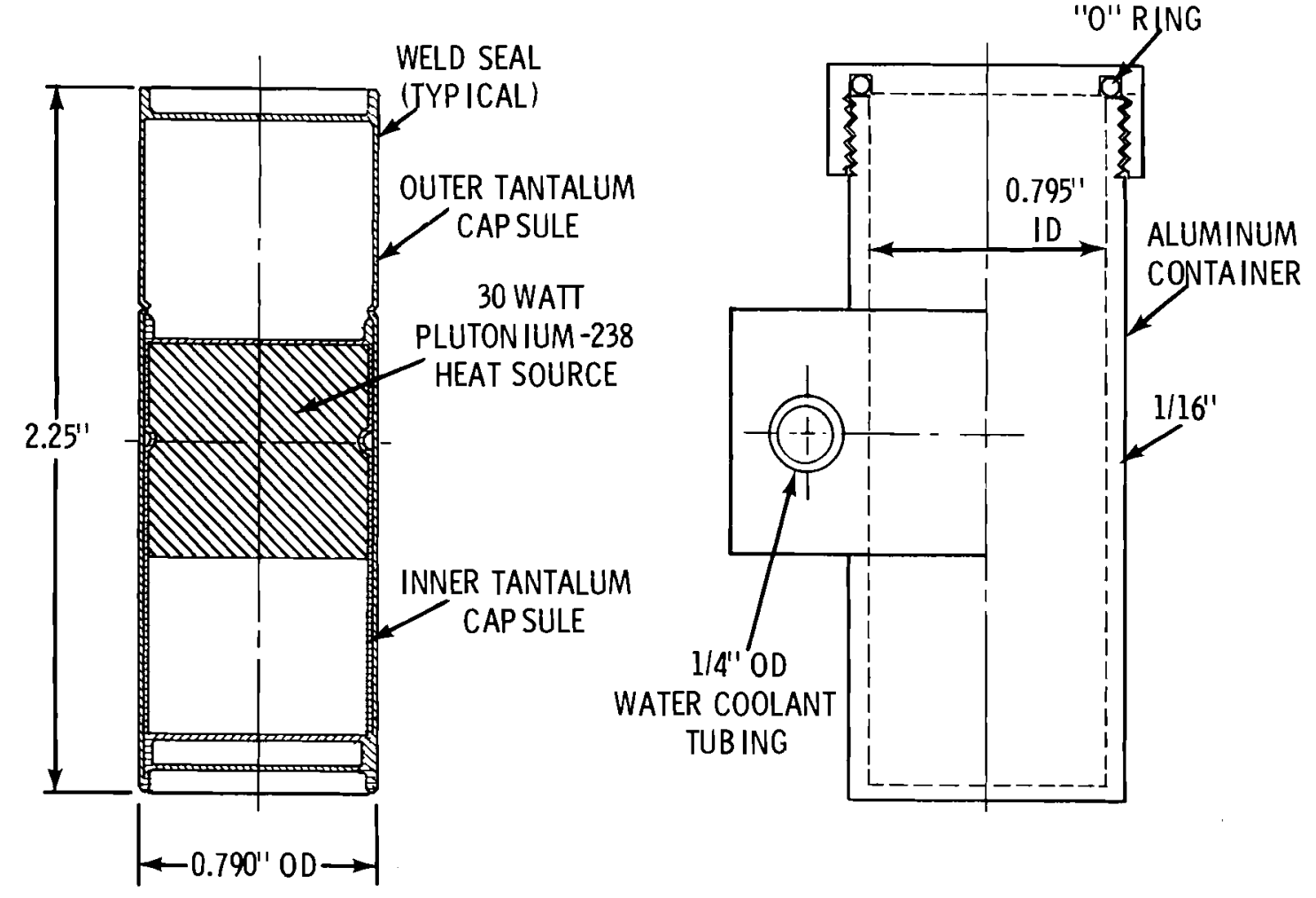

FIGURE 1. Schematics of LASL-1 and Heat Exchanger 


\section{I. GENERAL DESCRIPTION OF COMPUTATIONAL}

\section{CODES AND INPUT DATA}

Previous investigation ${ }^{(1)}$ has shown that the computer code QAD-P5A ${ }^{(2)}$ is capable of predicting the radiation dose from the ${ }^{146} \mathrm{Pm}$ impurity in a ${ }^{147} \mathrm{Pm}_{2} \mathrm{O}_{3}$ source surrounded by several shielding materials including a tissue-1ike medium. The computed dose rates were in good agreement with the experimentally determined values as long as the appropriate build-up factors were chosen. Because the computation of the photon dose rates from ${ }^{238} \mathrm{Pu}$ is similar, the majority of the effort in the dose rate predictions portion of the program has been devoted to clarifying the neutron contribution to the dose.

QAD-P5A is a point kernel code designed for computing photon and neutron dose rates from a volume-distributed radiation source. The shielding zones surrounding the source are defined in terms of intersecting planes and quadratic surfaces. A modified moments method is used for calculating the neutron dose rates. The modification essentially ignores the "infinite" medium restriction necessary for moments calculations and also generates a neutron spectrum for water rather than tissue. Because of the above approximations, the results would best be checked by other computational methods such as Transport and Monte Car1o. Subsequent sections will compare the dose rates derived by the different methods.

In anticipation of future computations involving complex geometric forms, such as the power source portion of the circulatory support system, the capacity of QAD has been enlarged to handle up to 500 boundaries, 500 zones, 500 compositions, 40 elements, 25 photon energy groups, and 8 million source kernels. In all probability, these capacities will not be needed for dose computations with the power source subsystems, 
but it is anticipated that upwards of 100 boundaries and zones would be required for approximating the geometries of some of the projected circulatory support subsystems. Some minor alterations of output format a1so have been made to conform with the desires of the authors.

In addition to these modifications, two portions of the QAD 1ibrary have been updated by incorporating the photon interaction coefficients of Storm and Israel(3) and the BachCaswe11(4) neutron fluence-to-kerma factors in the place of the earlier Snyder-Neufeld ${ }^{(5)}$ values. The Bach and Caswell conversion factors were selected as they are more recent and were considered to incorporate more accurate cross-section data. Ritts, Solomito, and Stevens ${ }^{(6)}$ have recently published fluence-to-kerma conversion factors but since their data, as applied to a fission spectrum, differ only slightly from the Bach and Caswell values, there was little choice between them. 


\section{LASL-1 PHOTON DOSE RATE COMPUTATIONS}

The ${ }^{238} \mathrm{Pu}$ abundances of Lederer, Asaro and Perlman (7) were used to compute the photon dose rates from a $30 \mathrm{~W}$ source placed centrally in a tissue phantom of $35 \mathrm{~cm}$ diam $\times 50 \mathrm{~cm}$ height. These abundances are presented in Table 3 . Note that disagreement exists in the literature on these abundances (for example, the values of LASL $^{(8)}$ are about $40 \%$ lower than the values in Table 3). Due to source self absorption and shielding by the surrounding tantalum and aluminum, most of the photons below about $200 \mathrm{keV}$ in energy do not significantly contribute to the dose rates in-phantom. In fact, $90 \%$ of the photon dose is found to be in the QAD-P5A energy range of 660 to $910 \mathrm{keV}$ with about $80 \%$ of this resulting from the ${ }^{238} \mathrm{Pu}$ $766 \mathrm{keV}$ gamma. This evidence has led the authors to conclude that ${ }^{137} \mathrm{Cs}$ would be a suitable "spiking" source for ${ }^{252} \mathrm{Cf}$ which is used to supply the fission neutron spectrum for simulating the ${ }^{238} \mathrm{Pu}$ radiations. Other 1aboratories have used ${ }^{90} \mathrm{Sr}-{ }^{90} \mathrm{Y}$ sources for this purpose and although it is a more logical choice when the simulation is for a thinly clad or bare ${ }^{238} \mathrm{Pu}$ source, it is a more complex source than is necessary for simulating the radiations from LASL-1 or any ${ }^{238} \mathrm{Pu}$ source that would be incorporated in a heat source subsystem for circulatory support.

The photon energy fluence-to-exposure conversion factors of Berger ${ }^{(9)}$ were used to convert the QAD-P5A output in $\mathrm{MeV} / \mathrm{cm}^{2}-\mathrm{sec}$ to units of $\mathrm{R} / \mathrm{hr}$. These exposure rate units were, in turn, converted to dose rate units, rads/hr, by multiplying by the appropriate f-factor (about 0.96) taken from NBS Handbook $85 .{ }^{(10)}$ Because a photon from LASL-1 may experience scattering in more than one material, an effective atomic number material would need to be selected for calculating the dose build-up. Goldstein's ${ }^{(1)}$ method for determining the 
TABLE 3. Energies and Intensities for Photons Assigned to $238 \mathrm{Pu}$ Alpha Decay

\begin{tabular}{|c|c|c|}
\hline Energy, keV & $\begin{array}{l}\text { Relative } \\
\text { Intensity }\end{array}$ & $\frac{\text { Photon }}{\text { Alpha }} \times 10^{7}$ \\
\hline $43.50 \pm 0.04$ & & 3800 \\
\hline $\mathrm{UK} \alpha_{2}$ & $315 \pm 30$ & $10.4 \pm 1.5$ \\
\hline $99.84 \pm 0.04$ & $28,000 \pm 2000$ & $920 \pm 60$ \\
\hline $\mathrm{UK}_{\mathrm{B}_{1}}^{\prime}$ & $238 \pm 55$ & $7.8 \pm 2.0$ \\
\hline $\mathrm{UK}_{\mathrm{B}_{2}}^{\prime}$ & $74 \pm 48$ & $2.4 \pm 1.6$ \\
\hline $152.71 \pm 0.05$ & $3865 \pm 250$ & $127 \pm 9$ \\
\hline $200.9 \pm 0.2$ & $15 \pm 3$ & $0.5 \pm 0.1$ \\
\hline $235.9 \pm 0.3 ?$ & $0.04 \pm 0.02$ & $0.001 \pm 0.0005$ \\
\hline $258.3 \pm 0.2$ & $0.35 \pm 0.05$ & $0.011 \pm 0.002$ \\
\hline $299.2 \pm 0.2$ & $0.20 \pm 0.05$ & $0.007 \pm 0.002$ \\
\hline $706.1 \pm 0.3$ & $0.42 \pm 0.06$ & $0.014 \pm 0.002$ \\
\hline $708.42 \pm 0.20$ & $1.15 \pm 0.09$ & $0.038 \pm 0.004$ \\
\hline $742.77 \pm 0.10$ & $23.2 \pm 0.4$ & $0.76 \pm 0.07$ \\
\hline $766.39 \pm 0.10$ & $\underline{100}$ & $3.3 \pm 0.3$ \\
\hline $786.30 \pm 0.10$ & $14.5 \pm 0.3$ & $0.48 \pm 0.04$ \\
\hline $805.8 \pm 0.3$ & $0.56 \pm 0.06$ & $0.018 \pm 0.002$ \\
\hline $808.25 \pm 0.15$ & $3.40 \pm 0.08$ & $0.11 \pm 0.01$ \\
\hline $851.70 \pm 0.10$ & $5.79 \pm 0.20$ & $0.19 \pm 0.02$ \\
\hline $880.5 \pm 0.3$ & $0.7 \pm 0.2$ & $0.023 \pm 0.003$ \\
\hline $883.23 \pm 0.10$ & $3.43 \pm 0.15$ & $0.11 \pm 0.01$ \\
\hline $904.37 \pm 0.15$ & $0.30 \pm 0.04$ & $0.010 \pm 0.002$ \\
\hline $926.72 \pm 0.15$ & $2.53 \pm 0.10$ & $0.083 \pm 0.008$ \\
\hline $941.9 \pm 0.2$ & $2.06 \pm 0.09$ & $0.067 \pm 0.007$ \\
\hline $946.0 \pm 0.3$ & $0.40 \pm 0.06$ & $0.013 \pm 0.002$ \\
\hline $1001.03 \pm 0.15$ & $4.39 \pm 0.14$ & $0.14 \pm 0.02$ \\
\hline $1041.8 \pm 0.3$ & $0.84 \pm 0.07$ & $0.028 \pm 0.003$ \\
\hline $1085.4 \pm 0.3$ & $0.34 \pm 0.04$ & $0.011 \pm 0.002$ \\
\hline
\end{tabular}


total build-up of a multilayer system was used. The total build-up factor depends on the number of mean free-path lengths penetrated by the radiation and on the "homogenized" effective atomic number $\bar{z}$ eff, where

$$
\bar{z}_{\text {eff }}=\frac{\sum_{\sum_{i}{ } d_{i}{ }^{\mu} i}{ }^{d}{ }_{i}^{\mu} i}{} .
$$

The total linear attenuation coefficient $\mu_{i}$ of layer $i$ is multiplied by $z_{\text {eff, } i} d_{i}$ where $d_{i}$ is the thickness and $z_{\text {eff, } i}$ is the effective atomic number of layer $i$. Following this procedure, the effective atomic numbers for LASL-1 in a homogeneous water phantom are about $92,89,78,68,60$, and 54 at source contact $(0 \mathrm{~cm}), 1 \mathrm{~cm}, 5 \mathrm{~cm}, 10 \mathrm{~cm}, 15 \mathrm{~cm}$, and $20 \mathrm{~cm}$ of $\mathrm{H}_{2} \mathrm{O}$, respectively. The equation indicates that the build-up factors for $\mathrm{H}_{2} \mathrm{O}$ are not applicable for any practical distance in a human size phantom. This is apparently evident in Figures 2 and 3 where the measured and computed dose rates, radially and axially, are compared. At the time these calculations were made, the QAD-P5A 1 ibrary did not contain build-up factors for some of the more useful materials, at least to experiments, 1 ike $\operatorname{Sn}(Z=50), \operatorname{Pm}(Z=61), \mathrm{Ta}(Z=73)$, and $U(Z=92)$. Some of these effective build-up materials will be employed in future computations. For the moment, the dose rate curves for iron and lead will be linearly interpolated to estimate the change in dose rate had the predicted build-up media been used. This can be done as build-up factors are smoothly varying functions of both atomic number and energy. Interpolating between iron and lead for promethium and tin, the 15 and $20 \mathrm{~cm}$ dose rates would become 1.94 and $0.990 \mathrm{mrads} /$ hr radially and 1.55 and $0.790 \mathrm{mrads} / \mathrm{hr}$ axially, respectively. These values are in good agreement with the measured doses. 


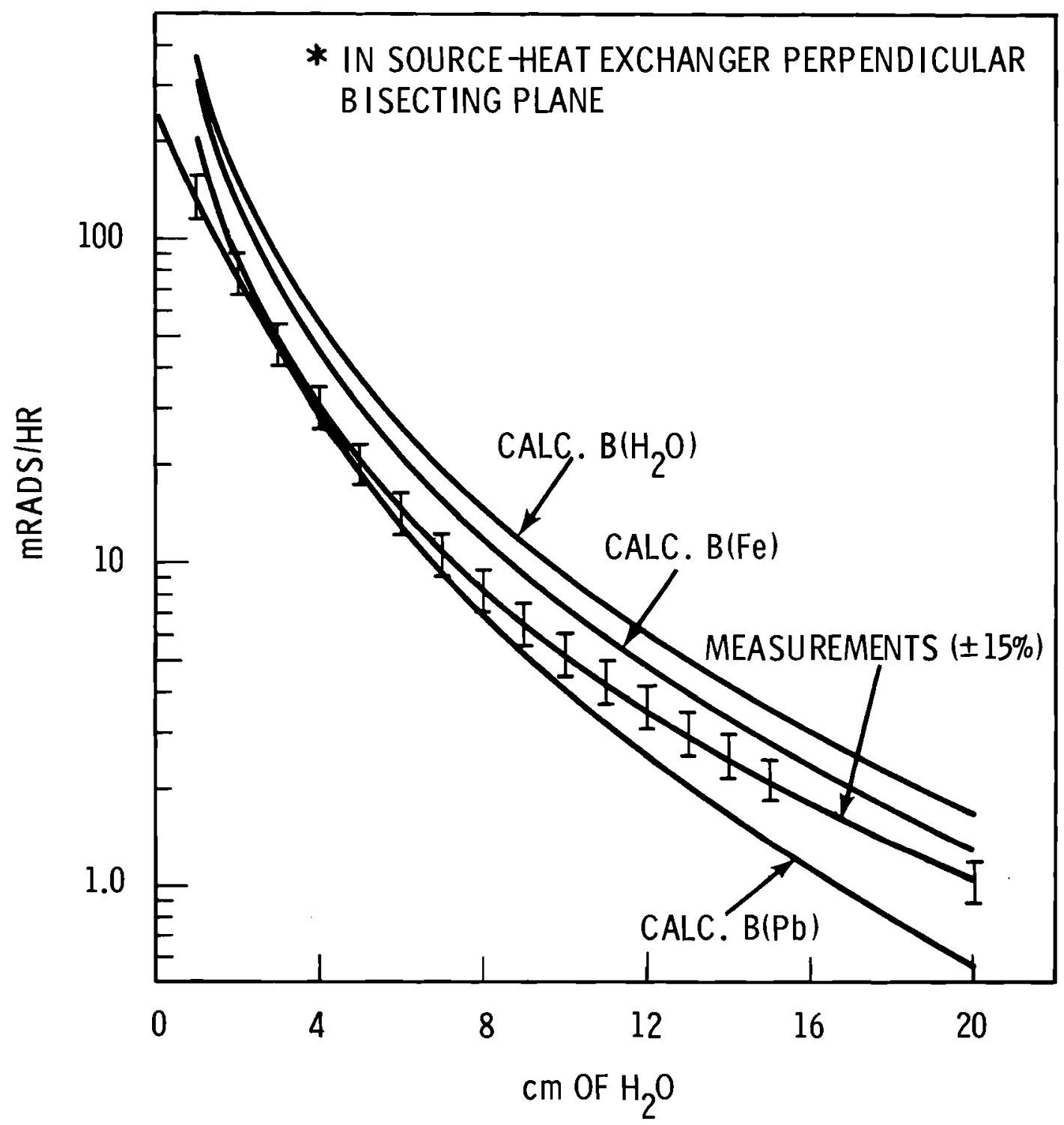

FIGURE 2. Comparison of LASL-1 Photon Measurements and Computations, Radially* 


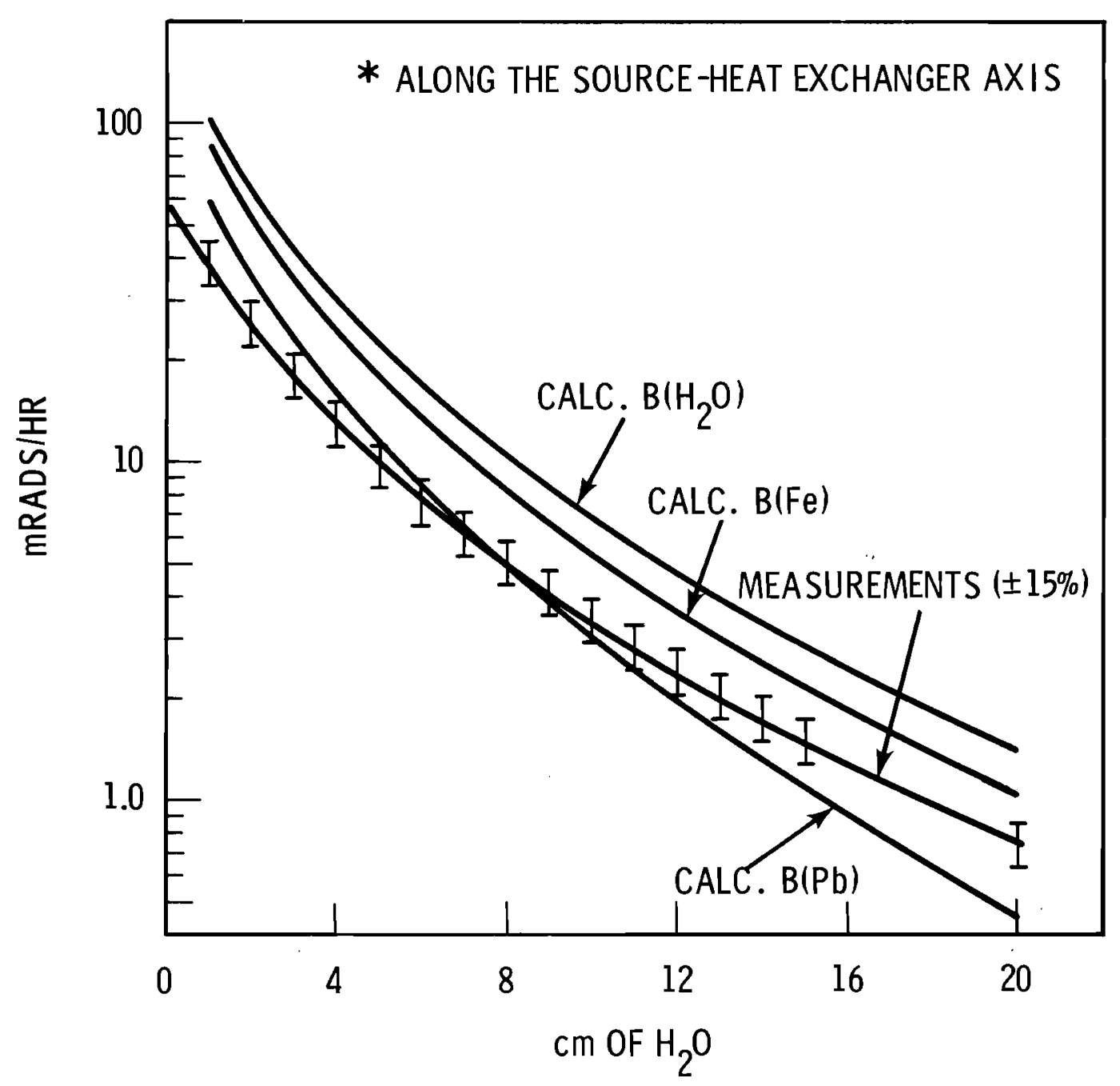

FIGURE 3. Comparison of LASL-1 Photon Measurements and Computations, Axially* 
Had uranium been employed for points nearer the source, the $1-\mathrm{cm}$ dose rate would have been 192 and $53.8 \mathrm{mrads} / \mathrm{hr}$ radially and axially, respectively. These values are slightly higher than the measurements, but two factors, probably in combination, could account for this. First, the predictions quite close to the source contain an inherently greater error. Second, the photon abundances employed in the computations are possibly too high. Evidence for the latter possibility are the lower photon intensities reported by LASL. It should be noted that Goldstein's equation does not predict the effective atomic number media for the previously reported ${ }^{147} \mathrm{Pm}_{2} \mathrm{O}_{3}$ measurements. The promethium calculations converged upon the measurements if the build-up factors for iron were used in the first $8 \mathrm{~cm}$ of tissue and if the build-up factors for water were used thereafter. In the present case, the atomic number starts high and progressively decreases when going from plutonium through tantalum, aluminum and water. In the former case, the atomic number started at about 52 for promethium oxide, decreased to iron, increased to tantalum or uranium, and decreased again to aluminum and water. In spite of the apparent applicability of Goldstein's equation for this case, it can only be concluded that predicting the correct build-up medium is not simple, and the computations must still be subject to the measurements.

Thus far, we have been concerned only with the radiations from initially pure ${ }^{238} \mathrm{Pu}$. Such a situation exists only when the impurities, notably any ${ }^{232} \mathrm{U}$ and ${ }^{236} \mathrm{Pu}$, remain insignificant. Eventually, the growth of ${ }^{236} \mathrm{Pu}$ daughters increases the photon dose rates, especially over a 10 -yr period which is the interim design goal for artificial heart system potency. For LASL-1, the photon dose rate at $10 \mathrm{~cm}$ into tissue would be increased by a factor of 4 after a period of $10 \mathrm{yr}$. A time estimate of this effect is shown in Figure 4 which contains the computed values for 


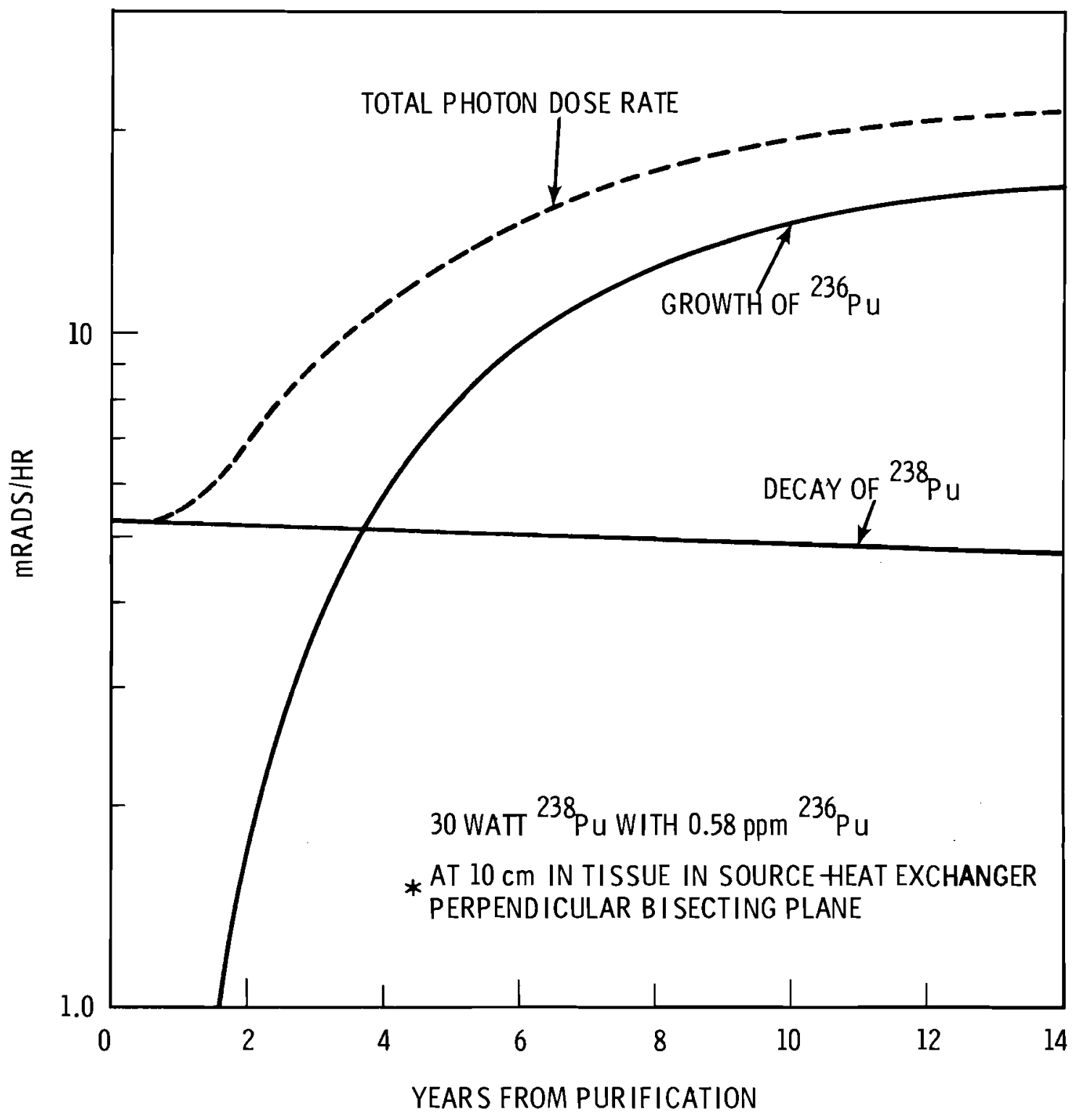

FIGURE 4. LASL-1 Photon Dose Rates as a Function of Time* 
${ }^{236} \mathrm{Pu}$ at $10 \mathrm{~cm}$ into tissue in the source-heat exchanger perpendicular bisecting plane. The build-up factors for lead were used in the computations. Although not evident in the figure, the ${ }^{236} \mathrm{Pu}$ growth peaks at about $18 \mathrm{yr}$. The figure also shows the slow decay of ${ }^{238} \mathrm{Pu}$ (nearly $8 \%$ in $10 \mathrm{yr}$ ). The ratio of the dose rates would be similar for other source directions. However, because the energies of the ${ }^{236} \mathrm{Pu}$ impurities are different from the ${ }^{238} \mathrm{Pu}$ radiations, the dose rate increase would be somewhat different for different tissue depths. The principal energies of concern are the 0.583 and $2.62 \mathrm{MeV}$ gammas of ${ }^{208} \mathrm{~T} 1$ since source self-absorption and the cladding remove most of the lower energy photons. In addition, the abundances of other contaminating gammas are 1 ow.

Future computations of in-phantom dose rates will be directed along three lines. First, computations will be made on the more complex heat source subsystems for circulatory support. Second, the growth of the doses from the source impurities will be determined. Third, the doses to various organ systems will be estimated. 


\section{LASL-I NEUTRON DOSE RATE COMPUTATIONS}

Two approaches were taken to corroborate the neutron dose rates computed with the modified, infinite-medium, moments method of QAD-P5A. First, the neutron fluences were computed in tissue-equivalent phantoms using the Transport and Monte Carlo codes. Appropriate conversion units were then used to convert these fluences to dose for comparison with the QAD-P5A values. Second, the doses determined by each of the computational methods were compared with the measurements made on a ${ }^{252} \mathrm{Cf}$ source.

The Battelle Monte Carlo code (BMC) ${ }^{(12)}$ was used to determine the energy deposited by various scattering processes, charged particle reactions, and the $H(n, \gamma) D$ reaction as a function of tissue-penetration by neutrons from point ${ }^{238} \mathrm{Pu}$ and ${ }^{252} \mathrm{Cf}$ sources placed centrally in a cylindrical tissue equivalent phantom of $35 \mathrm{~cm}$ diameter $\times 50 \mathrm{~cm}$ height. The scattering, charged particle, and $(n, \gamma)$ cross sections were derived from the Evaluated Nuclear Data File (ENDF/B) (13) and the tissue composition was taken from NBS Handbook 85. (10) The results of these computations are shown in Figure 5 which contains only the major contributors to the dose. The dose from fission spectra neutrons is largely caused by scattering, the proton and heavy element recoils, and the $H(n, \gamma) D$ reactions, although the dose contribution of the reaction gammas is 1 ess for cylindrical geometry than for slab geometry. Because rather large receiver volumes were used in the Battelle Monte Carlo code, no great accuracy in dose values is claimed; however, the fluences in the axial and radial directions were not found to be significantly different, and the data are in satisfactory agreement with Irving, Alsmiller, and Moran's data (14) for $2 \mathrm{MeV}$ neutrons (the approximate mean energy in a fission spectrum) in a tissue slab. 


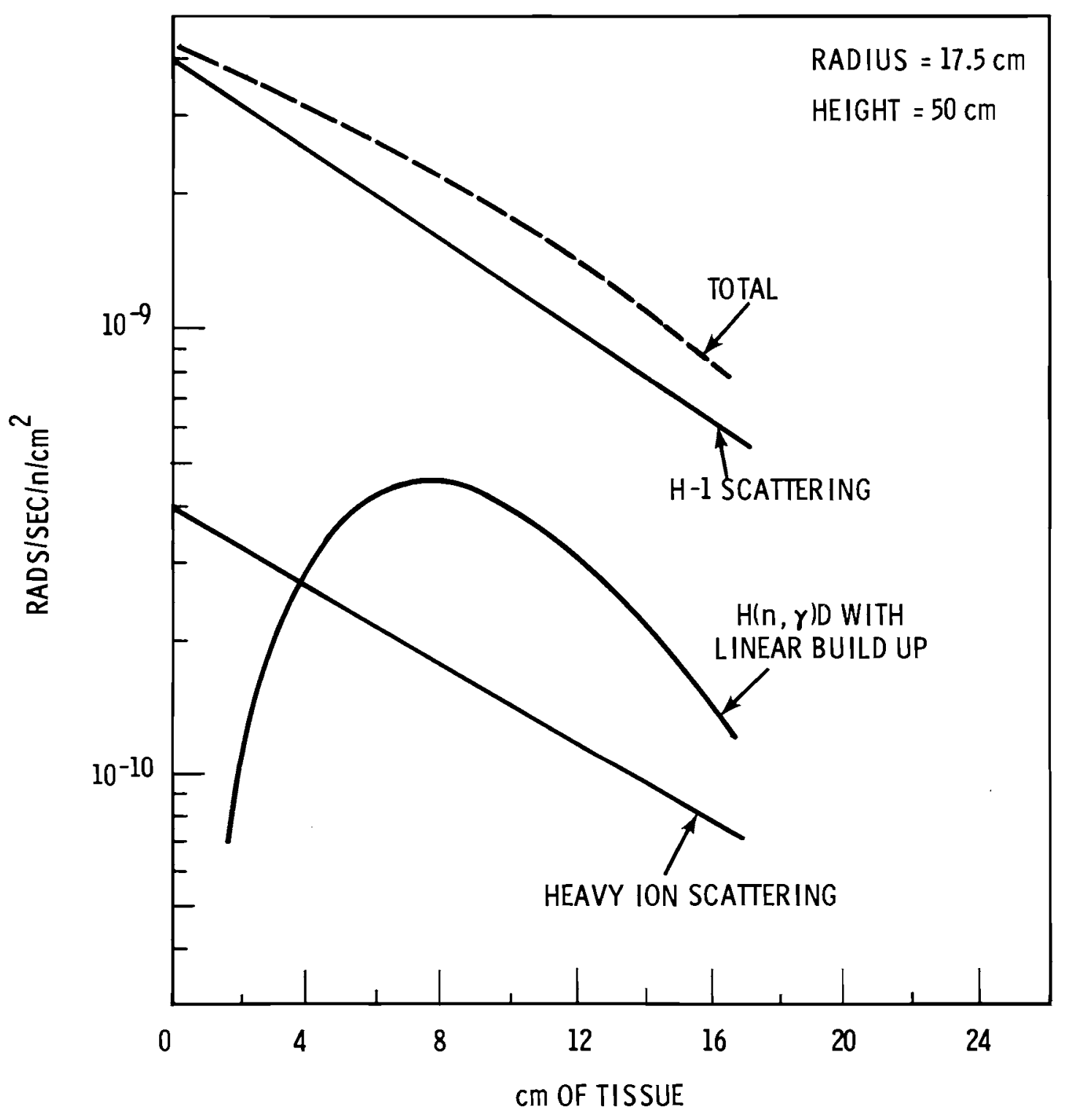

FIGURE 5. Monte Carlo Calculations for Fission Spectra Neutrons in a Cylindrical Tissue Phantom 
The transport code, ANISN, (15) was used to compute the neutron fluences for a ${ }^{252} \mathrm{Cf}$ source placed centrally in a spherical tissue phantom of $20 \mathrm{~cm}$ radius. The neutron fluences were again converted with the Ritts, Solomito and Steven's factors $(6)$ to determine the dose as a function of tissue penetration. Values for ${ }^{252} \mathrm{Cf}$ predicted with QAD-P5A, BMC and ANISN are shown in Figure 6 along with the first few centimeter measurements of Fairchild $(16)$ and supplemented with measurements made in this laboratory. The most recent measurements performed in this laboratory indicate even closer agreement with the QAD-P5A values than that indicated in Figure 6 .

Al1 three codes predict the ${ }^{252}$ Cf neutron dose rates quite well, and the geometry of the phantom was not found to influence the dose rates to an appreciable extent, at least in the first $15 \mathrm{~cm}$ or so of tissue. Beyond this depth, the neutron portion of the dose is a small enough fraction of the total (even more so for ${ }^{238} \mathrm{Pu}$ that any of the above codes could be said to satisfactorily predict the neutron dose rates from ${ }^{252} \mathrm{Cf}$ and especially from LASL-1 placed centrally in a human size phantom. The conclusion is that QAD-P5A, as modified above, can adequately predict the neutron dose rates from implanted ${ }^{238} \mathrm{Pu}$ sources, at least in the region where the neutrons contribute their greatest dose.

Figures 7 and 8 compare the LASL-1 neutron measurements and QAD-P5A computations, radially and axially, respectively. The LASL-1 measurements, which will be described later, were derived from ${ }^{252}$ Cf measurements and cross-checked with a few direct neutron measurements on the ${ }^{238} \mathrm{Pu}$ source. For those points near the source, especially in Figure 7 , the computations are probably more meaningful than the measurements, since the proportional counter dosimeters were too large to 


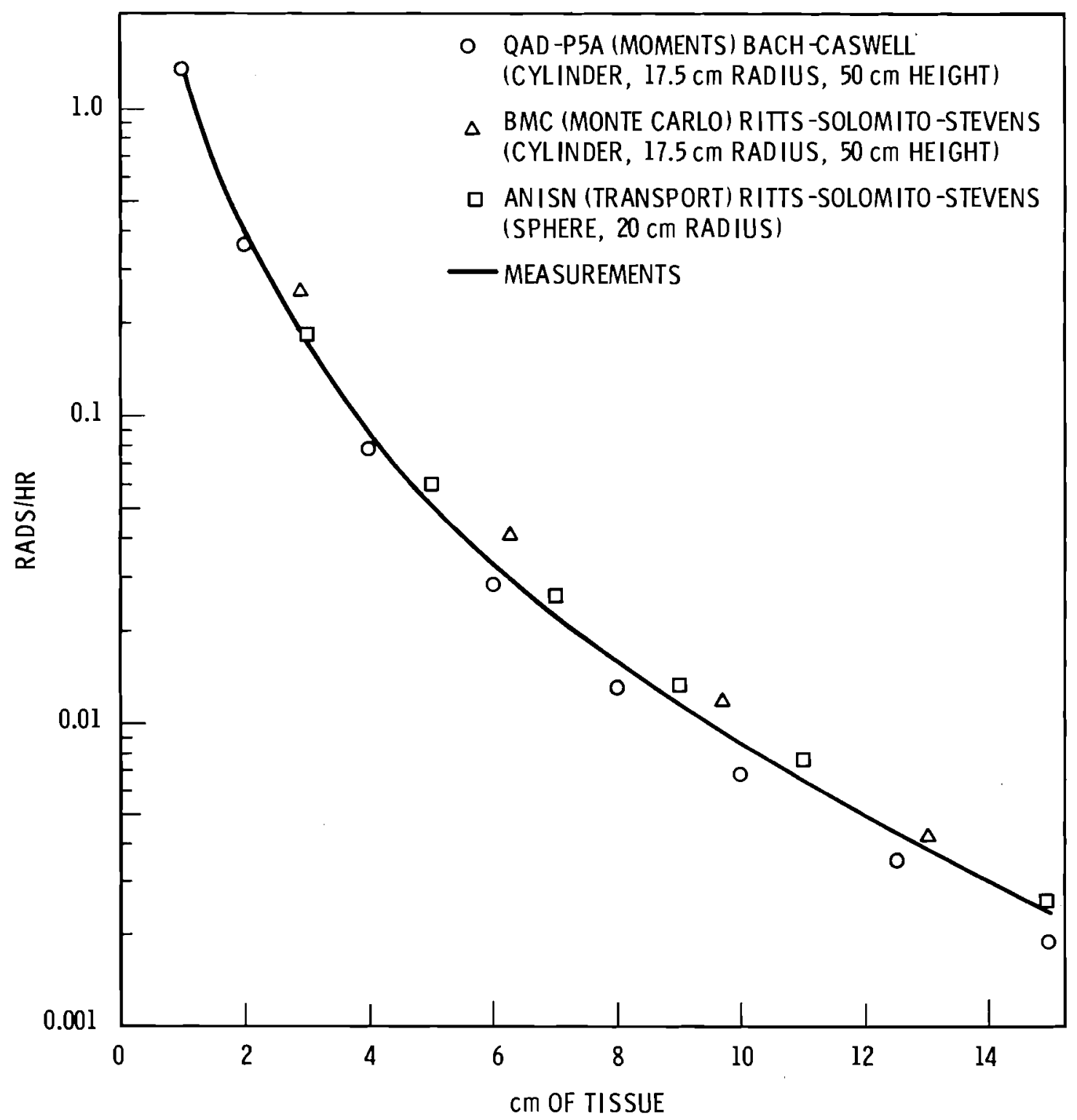

FIGURE 6. Neutron Dose Rates in Tissue for a $1.0 \mu \mathrm{g}{ }^{252} \mathrm{Cf}$ Source 


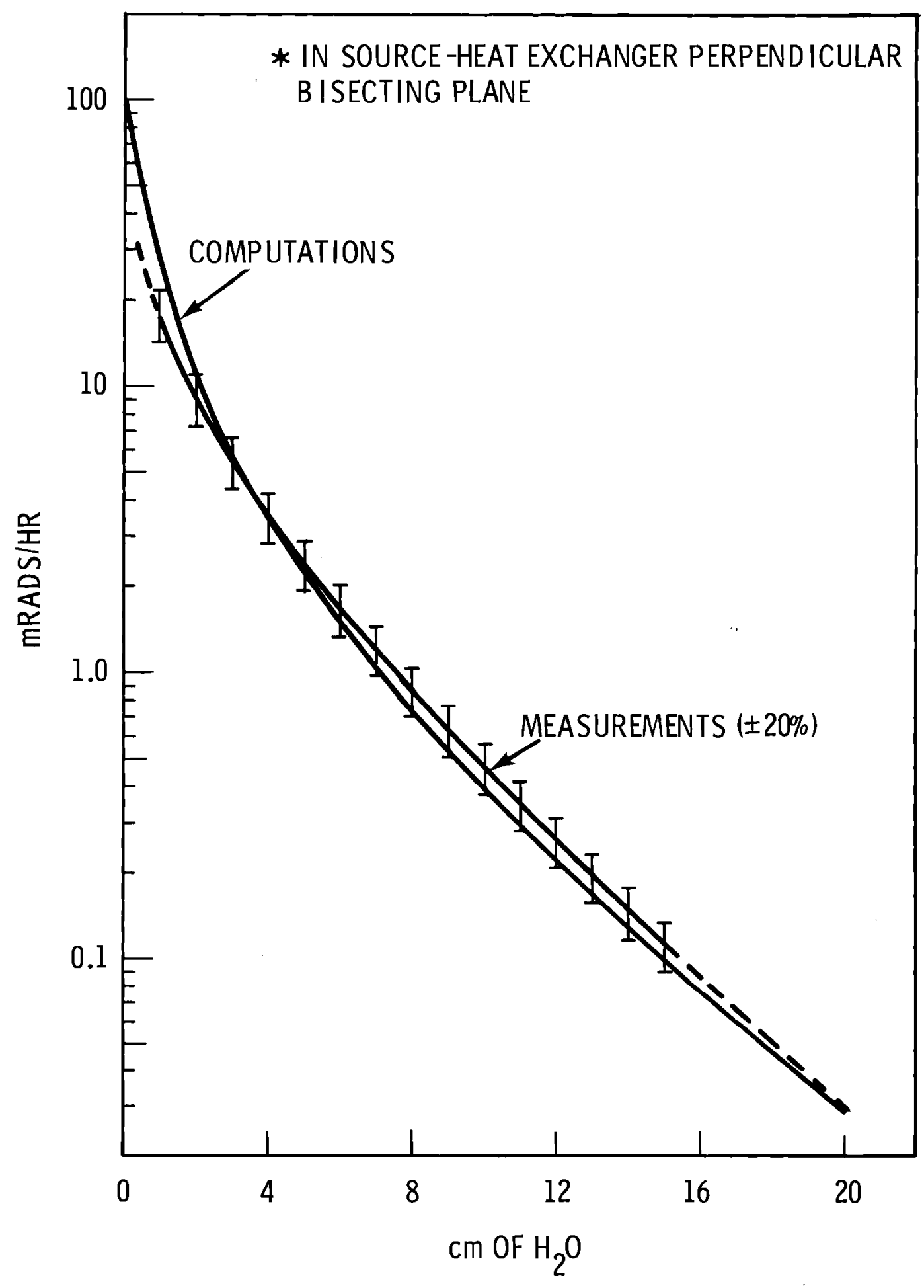

FIGURE 7. Comparison of LASL-1 Neutron Measurements and Computations, Radially* 


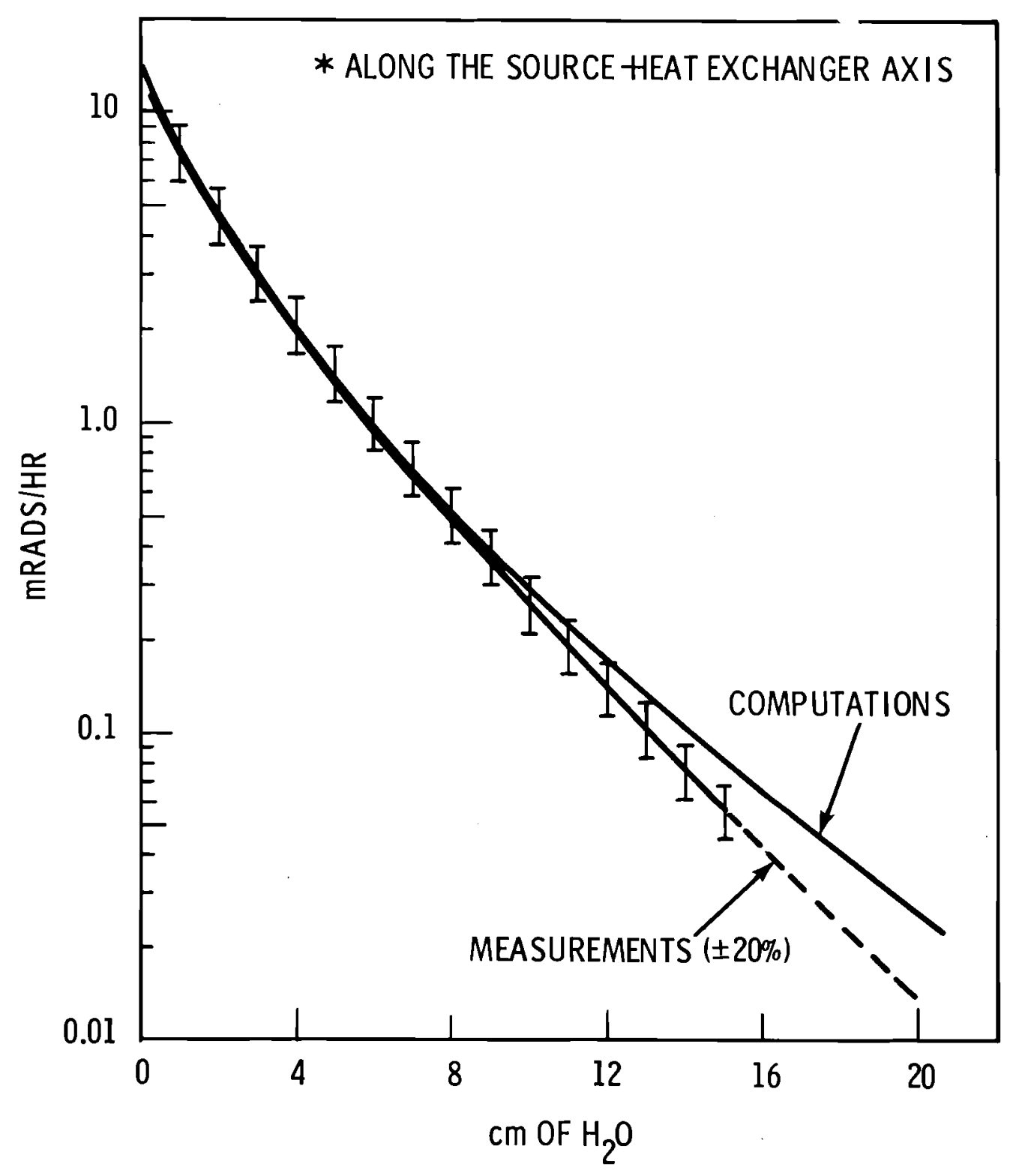

FIGURE 8. Comparison of LASL-1 Neutron Measurements and Computations, Axially* 
accurately measure the neutron dose rates in the first few centimeters. At the greater thicknesses, the radial measurements and predictions are practically indistinguishable, whereas the axial values diverge somewhat. In both sets of measurements, the statistics are poorer at the greater thicknesses because of proportional counter gas deterioration resulting from the required long measurement times. Because of the source geometry, equal tissue or water thicknesses actually represented larger sourcecenter, dosimeter-center distances in the axial direction, requiring even longer measurement times. In addition, the cylinder boundaries were approached more closely in the axial measurements where some of the radiations could have escaped rather than backscattered to the dosimeter. Because the dosimeter is biased to exclude the measurement of photons while the reaction gammas are included in the computations, it could be expected that the measurements and calculations will never quite agree. However, the $(n, \gamma)$ contribution is small (see Figure 5), and in any event, would apply to the data of Figure 7 as wel1 as Figure 8 . Some of these measurements will be repeated in future experiments but with the accumulation of the data in increments of time precluding the possibility of gas deterioration. Note that the accuracy of the neutron dose rates does not necessarily have to be as high at these tissue thicknesses since their contribution to the total $(n+\gamma)$ physical dose rate is small (for example, $0.025 \mathrm{mrads} / \mathrm{hr}$ at $20 \mathrm{~cm}$ compared with a gamma dose rate of $0.75 \mathrm{mrads} / \mathrm{hr}$ at the same axial point).

We should mention the differences in media appearing in the various figures. Some of the measurements were performed with the phantoms filled with water rather than tissue fluid. Although either medium is suitable for the photon measurements, we did not know this to be the case for the neutrons until measurements in the two media were found to agree 
within experimental error and with the calculated values. The QAD-P5A neutron dose rate computations utilize a momentsgenerated neutron spectrum in water, Bach-Caswell conversion factors, and a water removal cross section. The BMC and ANISN codes use somewhat different parameters but include tissue, and as can be seen in Figure 6, the agreement in the measurements and computations is good, at least in the first $15 \mathrm{~cm}$ of tissue (or water). In addition, the theoretical cylinder phantom data of Auxier, Snyder, and Jones (17) was found to be in essential agreement with the data of Figure 6. Any disagreement beyond $15 \mathrm{~cm}$ thicknesses becomes less consequential for the reasons stated previously.

Calculations utilizing the Irving-Alsmiller-Moran dose conversion factors (14) indicate that the neutron dose in water could be 4 to $5 \%$ higher than in tissue and that this difference applies out to at least a $15 \mathrm{~cm}$ thickness. This small difference is due to a fortuitous cancellation of effects. The increased dose in water from the higher hydrogen atom content is somewhat offset by the absence of the ${ }^{14} \mathrm{~N}(\mathrm{n}, \mathrm{p}){ }^{14} \mathrm{C}$ reaction in tissue. Practically, the differences in the media have not been resolved experimentally, and it can be concluded that water is a suitable substitute for tissue in these experiments.

Finally, a simplified neutron dose equation similar to that developed by Barr and Hurst (18) was synthesized from all the computations and measurements obtained during this program. In addition to the previously mentioned references, the works of Oliver(19) and Wright (20) were found useful in deriving the equation. Because of its simplicity, the accuracy is not expected to be as good as the computer predictions for all points in tissue space. It is intended to be a quick method for estimating the neutron dose rates from implanted fission 
spectrum sources. The simplified equation agrees within $15 \%$ of the QAD-P5A LASL-1 predictions, both radially and axially, in the range of 1 to $20 \mathrm{~cm}$ in tissue.

The equation is as follows:

$D_{x+R}(\operatorname{rads} / \mathrm{hr})=\frac{1.08 \times 10^{-5} \text { (Neutron Emission Rate) } \mathrm{e}^{-\mathrm{x} / 8.22}}{4 \pi(\mathrm{x}+\mathrm{R})^{2}}$

where $x$ and $R$ are the tissue and void (noninteracting) thicknesses, respectively. For a nominal 30-W medical-grade ${ }^{238} \mathrm{Pu}$ product, the neutron emission rate is $1.67 \times 10^{5} \mathrm{n} / \mathrm{sec}$. 


\section{LASL-1 PHOTON DOSE RATE MEASUREMENTS}

The in-phantom dosimetry measurements were performed utilizing the same phantoms and similar techniques described in the final report on the ${ }^{147} \mathrm{Pm}_{2} \mathrm{O}_{3}$ measurements. (1) However, because the radiations from ${ }^{238} \mathrm{Pu}$ contain neutrons in addition to photons, different dosimeters were employed in these measurements. In particular, the extrapolation-ionization chamber formerly used would respond significantly to both radiations and confuse the interpretation of the measurements.

The original experimental approach was to measure the photon dose rates with small aluminum-wall ionization chambers and the combined neutron and photon dose rates with similar chambers constructed of tissue equivalent (TE) materials. These measurements were not altogether successful due to an uncertainty in the chamber calibrations and the fact that the aluminum chambers responded to the fission neutrons. Although the aluminum chambers were excellent dosimeters in most pure gamma fields, their response was generally slightly high when compared with similarly calibrated TLD-700 thermoluminescent dosimeters. The advantage of the ionization chambers over the TLD-700 + proportional counter method, the method finally used, was their smaller size and, therefore,greater inherent accuracy for measurements very close to the source. In fact, a combination of TLD-700, smaller yet than the aluminum chambers, and the $\mathrm{TE}$ chambers measured neutron dose rates that were in close agreement with the various ${ }^{252} \mathrm{Cf} 1$ iterature values. $(16,19,20)$ Because of their low sensitivity, the chambers were not satisfactory for dose measurements far from the source. Since neutron doses had to be derived by a subtraction method and smaller proportional counters became available, the ionization chamber method was dropped. 
The photon dose rates, therefore, were measured exclusively with TLD-700 blocks, 0.125 in. $\times 0.125$ in. $\times 0.35$ in., known to be insensitive to the neutrons from ${ }^{252} \mathrm{Cf}$ and ${ }^{238} \mathrm{Pu}$ sources. The blocks were Roentgen calibrated with ${ }^{226} \mathrm{Ra}$, and their measurements were converted to tissue rads with the appropriate f-factor. Measurements were made in a homogenous water-filled phantom (a cylinder of $35 \mathrm{~cm}$ diameter $\times 50 \mathrm{~cm}$ height) and in a Remab phantom. The sources were placed centrally (somewhat nearer the bottom) in the homogenous phantom and on the inside surface of the left ilium in the Remab phantom with their axes parallel to the Remab center axis. The exposure conditions in the homogenous phantom were such that full dose build-up was ensured. Figures 9 and 10 detail the measurements for the homogenous phantom space lying above the source's heat-exchanger end surface. The measurements along the axis and in the source perpendicular bisecting plane are shown in Table 4 .

The measurements in the Remab phantom will be included in Section VII along with the neutron dose rates. 
BNWL - 1489

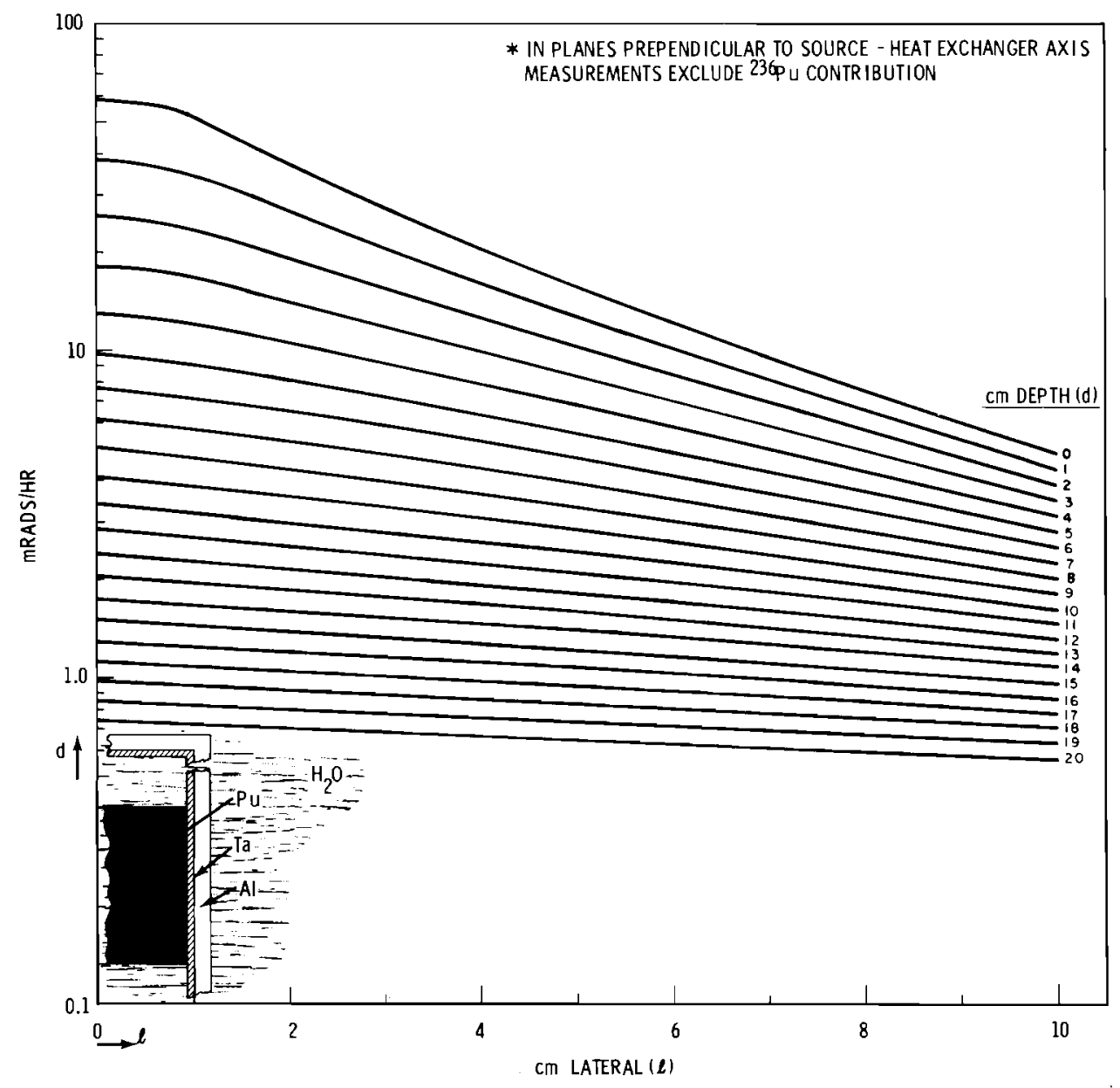

FIGURE 9. LASL-1 In-Phantom Photon Dose Rates, Radial Planes* 


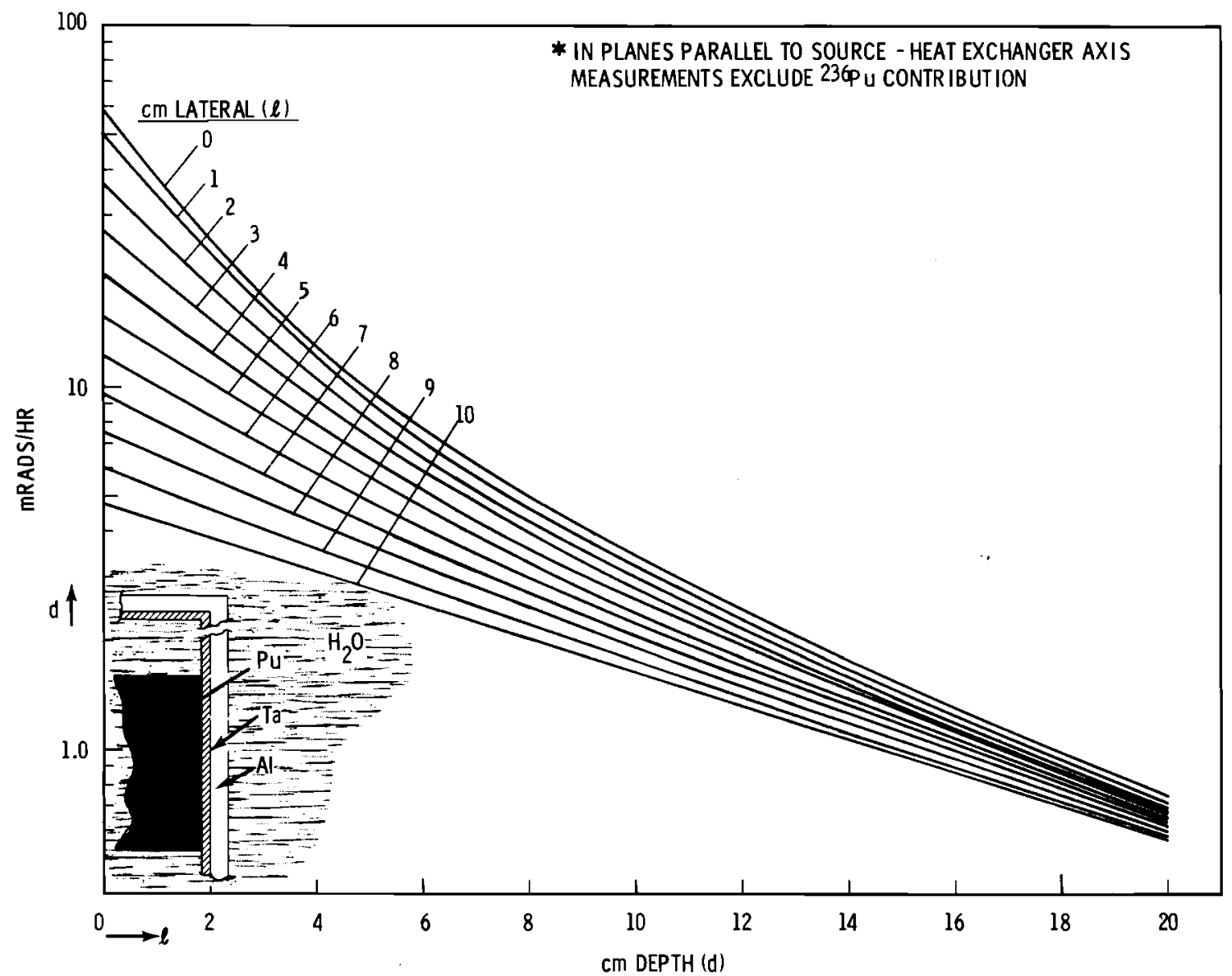

FIGURE 10. LASL-I In-Phantom Photon Dose Rates, Axial Planes* 
TABLE 4. LASL-1 In-Phantom Photon Dose Rates (mrads/hr $\pm 15 \%$ )

Tissue

Thickness, cm

0

1

2

3

4

5

6

7

8

9

10

11

12

13

14

15

20

\begin{tabular}{ccc} 
Radial & & Axial \\
\hline 240 & & 58.4 \\
136 & 38.6 \\
78.3 & & 25.8 \\
47.6 & 18.0 \\
30.3 & 13.0 \\
20.3 & 9.76 \\
14.3 & 7.69 \\
10.6 & 6.18 \\
8.30 & 5.06 \\
6.57 & 4.14 \\
5.28 & 3.42 \\
4.32 & 2.86 \\
3.63 & 2.41 \\
3.03 & 2.04 \\
2.58 & 1.76 \\
2.16 & 1.51 \\
1.04 & 0.747
\end{tabular}




\section{LASL-1 NEUTRON DOSE RATE MEASUREMENTS}

Tissue-equivalent proportional counters (TEPC's), patterned after the development by Hurst, (21) were employed with the techniques of Rossi(22) and Glass (23) to measure the neutron dose rates from implanted ${ }^{252} \mathrm{Cf}$ and ${ }^{238} \mathrm{Pu}$ sources. The proportional counter consists of a sphere of tissueequivalent (TE) plastic surrounding a cavity filled with TE gas at a pressure chosen to simulate small 2- $\mu$ diam tissue sites. A pulse height discriminator was used to reject gamma interference. Further information on the operation of the counter can be found in various chapters of the textbooks Radiation Dosimetry (see Reference 17) and, in particular, the studies by Endres, Glass and Haverfield. (24)

The details of these experiments were similar to the photon measurements. The proportional counters (originally 2 -in. $O D$, but changed to $1 / 2$-in. $O D$ ) were supported on ring stands in a manner which minimized extraneous material from being interposed between the source and detector. In most cases, separation distances were measured with a cathetometer. In-phantom neutron measurements were made on (1) a "bare" ${ }^{252} \mathrm{Cf}$ source (the approximate 7 - $\mu \mathrm{g}$ source was about $1 / 8$-in. diam $\times 1 / 4-i n$. long, fused in quartz and sealed in stainless steel of wall thickness $=0.030$ in.), (2) on the ${ }^{252} \mathrm{Cf}$ source placed centrally in the LASL-1 heat exchanger, and (3) on the LASL-1 ${ }^{238} \mathrm{Pu}$ source placed in this heat exchanger. Even in contact with the source-heat exchanger surface, the center of the 1/2-in. TEPC chamber is $1 \mathrm{~cm}$ away; therefore, the accuracy is lower for the measurements in the first few centimeters of tissue especially in the LASL-1 radial direction.

Because the neutron emission rate for LASL-1 is low and limits dose measurements close to the source, ${ }^{252} \mathrm{Cf}$ was used 
as a substitute to extend the range of dose measurements. Both 252 Cf and LASL-1 are fission sources with similar mean neutron energies; thus, it would be expected that if they are similarly contained, the only difference in their neutron dose rates would arise from their different neutron emission rates. The measurements confirmed this; therefore, most of the LASL-1 neutron dose rates were derived from the ${ }^{252} \mathrm{Cf}$ source placed in the heat exchanger. The intensities of the two neutron sources were determined with a long-counter in a relatively scatter-free environment. Although the absolute emission rates of the sources could not be measured to better than perhaps 10 to $15 \%$, the relative emission rates are subject to error cancellation and can be claimed to be no more than a few percent in error. The LASL-1 measurements along the axis and in the source perpendicular bisecting plane are shown in Table 5. No greater detail in neutron measurements was attempted because we felt that the dose rates for other points in the phantom could be derived from these measurements or calculated satisfactorily with the equation or methods in Section $V$.

TABLE 5. LASL-1 In-Phantom Neutron Dose Rates (mrads/hr \pm 208 ) *

Tissue Thickness, cm

1
2
3
4
5
6
7
8
9
10
11
12
13
14
15

\begin{tabular}{l} 
Radia1 \\
\hline 17.9 \\
9.10 \\
5.51 \\
3.56 \\
2.42 \\
1.69 \\
1.22 \\
0.884 \\
0.640 \\
0.473 \\
0.351 \\
0.262 \\
0.197 \\
0.148 \\
0.113
\end{tabular}

Axial

7.50

4.69

3.09

2.11

1.46

1.02

0.722

0.514

0.371

0.267

0.194

0.142

0.104

0.077

0.0565

* Derived mainly from ${ }^{252}$ Cf measurements 
The measurements in and about the Remab phantom are shown in Figures 11,12 , and 13 . In a 11 cases, the sources were placed on the inside surface of the left ilium, in the indicated position. The neutron dose rates were derived from ${ }^{252} \mathrm{Cf}$ measurements (some were interpolated from the measurements in the homogenous phantom), but the photon dose rates were measured with LASL-1. The figures contain the sum of the neutron and photon dose rates excluding the ${ }^{236} \mathrm{Pu}$ contribution which was negligible during these measurements.

Figure 11 shows some measurements on the surface of the Remab phantom. In no case was the neutron contribution to the physical dose greater than about $15 \%$. The measurements further from the source (for example, the shoulder) indicated that the contribution was more on the order of $1 \%$. Once the RBE of these radiations becomes established, the biological dose or dose equivalent can be calculated. In the meantime, following established health physics practices by rote, a quality factor of 10 would be selected. This would increase the dose rates nearer the source (now in mrem/hr) by about a factor of 2 and leave the other dose rates essentially unchanged.

Figure 12 is similar to Figure 11 except that the surface dose rates are measured in the bisecting radial plane of the source and $1 \mathrm{ft}$ and $3 \mathrm{ft}$ from the body surfaces. Because the measurements are in the highest dose rate plane, the values in Figure 12 represent the maximum 1 ikely to be found external to the Remab phantom. Again, the neutron contribution to the total physical dose does not exceed about $15 \%$, and again, by using the rules above, the dose equivalent (mrem/hr) would not exceed about twice any of these values.

Figure 13 shows the dose rates along the central axis of the Remab phantom. In this case, the neutron dose rates were 


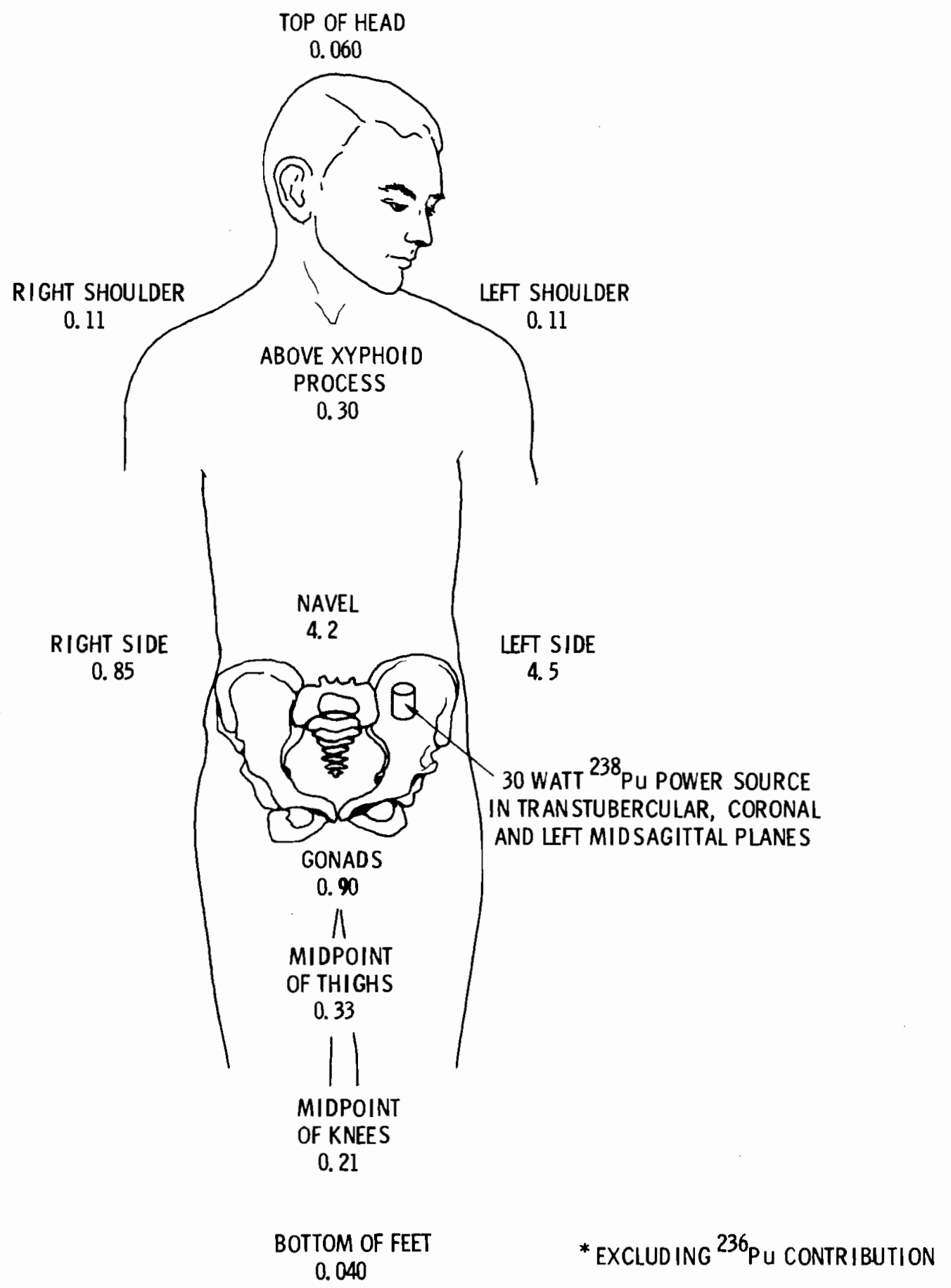

FIGURE 11. Total $(n+\gamma)$ Dose-Rates in mrads/hr on Surface of Remab Phantom* 


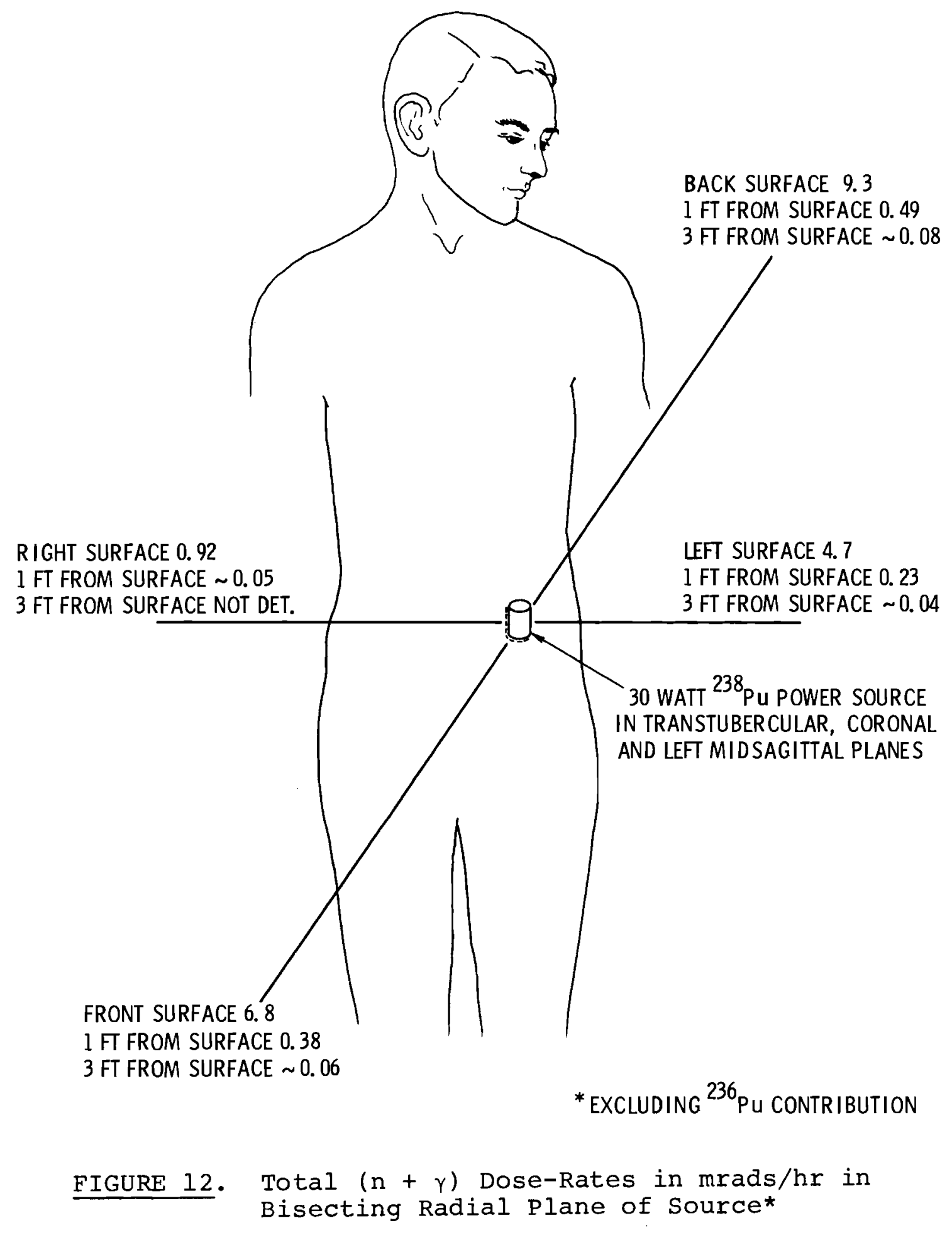


BNWL - 1489

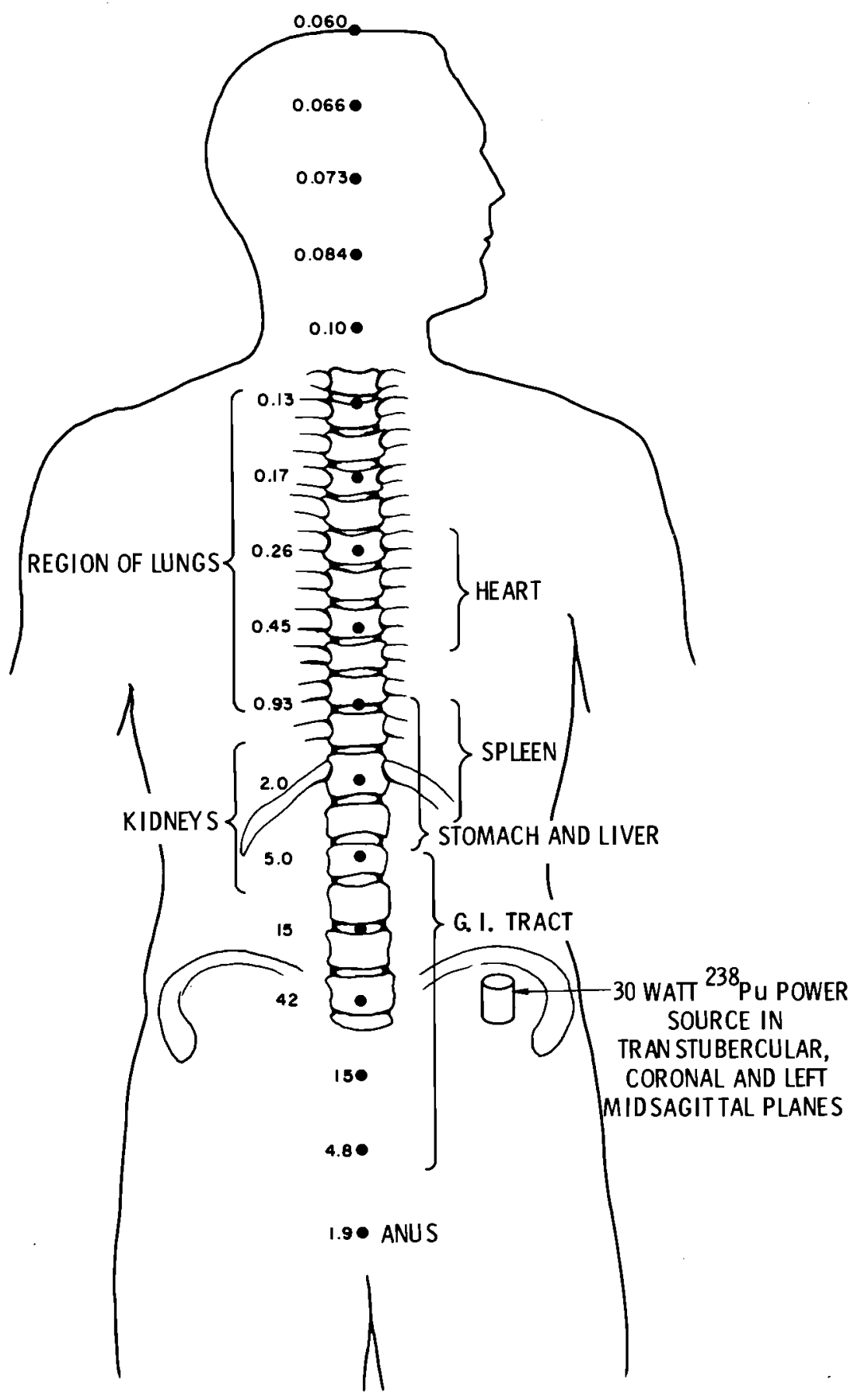

FIGURE 13. Total $(n+\gamma)$ Dose-Rates in mrads/hr Along Central Axis of Remab Phantom 
derived from the ${ }^{252}$ Cf measurements in the homogenous phantom. The justification for this is the relatively constant fluenceto-kerma factors for lung $\left(3.01 \times 10^{-7} \mathrm{erg} / \mathrm{g} / \mathrm{n} / \mathrm{cm}^{2}\right.$ at $\left.2 \mathrm{MeV}\right)$, standard man $\left(2.995 \times 10^{-7}\right)$, muscle $\left(2.97 \times 10^{-7}\right)$, and bone $\left(2.29 \times 10^{-7}\right)$, as determined by Ritts, Solomito, and Stevens. In these measurements, the neutron contribution to the total dose rate varied from 1 ess than $1 \%$ for points furthest from the source to no more than about $15 \%$ (actually $13 \%$ was the maximum contribution found in any of the measurements of Figures 11 , 12 , and 13) for points closest to the source. Therefore, the dose equivalents would be similarly increased as for Figures 11 and 12. The vertical scale of Figure 13 contains the 17 measurements in a length of about $93 \mathrm{~cm}$ while the horizontal scale is out of proportion in order to make the presentation clearer. The regions of various organ systems are shown for reference only. The dose rates are not to be assumed to apply to them. In fact, only those organs lying quite close to the central axis of the body and which have a small lateral spread would be expected to have similar dose rates. 
BNWL - 1489

\section{CONCLUSIONS}

In conclusion, the dose rates from LASL-1 are satisfactorily calculated using the modified code QAD-P5A. It is expected that the computed photon dose rates will agree even more closely with the measured dose rates once the discrepancies in emission rate are removed and the dose build-up factors are determined more precisely. For practical purposes, no further improvement is needed in the neutron dose rate computations. The agreement with measured values is good, and the neutron dose contribution is a small fraction of the total dose, except for positions quite close to the source where the contribution to the dose equivalent would be about $50 \%$ if a neutron quality factor of 10 is chosen.

Future experimentation will establish the perturbation of prototypic heat source subsystems and source impurities on the dose rates and will detail the doses absorbed by various organ systems.

The previous measurements on promethium heat sources indicated that a nominal $1.2 \mathrm{lb}, 15-\mathrm{W}$ shielded source with $0.25 \mathrm{ppm}{ }^{146} \mathrm{Pm}$ impurity would produce a dose rate at the level of the spleen (about $20 \mathrm{~cm}$ away) of 20 to $35 \mathrm{mrem} / \mathrm{hr}$ depending on the source orientation. At the same location, the nominal $30-W$ plutonium source and shields weighing about $0.41 \mathrm{~b}$ produces dose rates on the order of 1 to $1.5 \mathrm{mrem} / \mathrm{hr}$ using a quality factor of 10 for the neutrons. A1though the $0.58 \mathrm{ppm}^{236} \mathrm{Pu}$ will grow in to increase the dose rates from a plutonium source, this disadvantage is nullified by the fact that a comparably useful promethium heat source would produce dose rates about four times higher, or on the order of $100 \mathrm{mrem} / \mathrm{hr}$ at $20 \mathrm{~cm}$ into tissue. A factor of 2 accounts for the difference in thermal watts and another factor of about 2 is required because the half 1 ife of promethium is much shorter than 
plutonium. Unless the ${ }^{146} \mathrm{Pm}$ impurity is further reduced, plutonium is a more advantageous source. The dose comparison would be somewhat different at closer positions to the sources, but essentially similar conclusions would be reached. 


\section{ACKNOWLEDGEMENTS}

The authors would like to acknowledge the contributions of L. W. Brackenbush who measured the neutron emission rates of the LASL-1 and ${ }^{252}$ Cf sources, G. L. Simmons who assisted in the Monte Carlo and Transport calculations, and U. L. Upson who did the calorimetry of LASL-1. 
BNWL - 1489

\section{REFERENCES}

1. F.T. Cross and J. C. Sheppard. "In-Phantom Dosimetry of $147 \mathrm{Pm}_{2} \mathrm{O}_{3}$ Heat Sources in Relation to Circulatory-Support Systems," Isotopes and Radiation Technology, vor. 7, p. 231. 1969 .

2. R. E. Malenfant. QAD: A Series of Point-Kernel General Purpose Shielding Programs, LA-3573. Los Alamos Scientific Laboratory, March 1967 .

G. P. Lahti. QADHD Point-Kernel Radiation Shielding Computer Code to Evaluate Propeliant Heating and Dose to Crew During Engine operation, NASA-TM-X-1397. National Aeronautics and Space Administration, Lewis Research Center, Cleveland, ohio, June 1967.

Copies of $Q A D$ can be obtained from

Radiation Shielding Information Center oak Ridge National Laboratory

Post office Box X

oak Ridge, Tennessee 37831

3. E. Storm and H. I. Israel. Photon Cross Sections from 0.001 to $100 \mathrm{MeV}$ for Elements 1 Through 100, LA-3573. Los Alamos Scientific Laboratory, June 1967.

4. R. L. Bach and R. S. CaswezZ. "Energy Transfer to Matter by Neutrons," Radiation Res., vol. 35, p. 1. 1968.

5. W. S. Snyder and J. Neufezd. "Calculated Depth Dose Curves in Tissue for Broad Beams of Fast Neutrons," Brit. J.Radiol., vol. 28, p. 342. 1955.

6. J.J.Ritts, M. Solomito, and P. N. Stevens. "Calculation of Neutron Fluence-to-Kerma Factors for the Human Body," Nucl. Appl. and Tech., vol. 7, p. 89. 1969.

7. C. M. Lederer, F. Asaro, and I. Perlman. The Nuclear

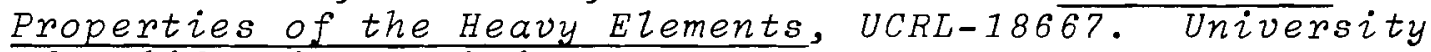
of California, Berkeley.

8. R. D. Baker. Progress Report for September, 1968 - Preparation and Evaluation of $238 \mathrm{Pu}$ Radioisotopic Heat Sources, CMB-1483. Los Alamos Scientific Laboratory, October 1968.

9. H. Goldstein. Fundamental Aspects of Reactor Shielding. Addison-Wesley Publishing Co., Inc., Reading, Massachusetts, 1959. p. 17 .

10. ICRU. "Physical Aspects of Irradiation," Nat. Bur. Std. Handbook 85, U.S. Government Printing office, Washington, D.C., 1964 . 
11. R. G. Jaeger et al. Engineering Compendium on Radiation Shielding, Vol. I. Springer-Verlag, Inc. New York, 1968. p. 230 .

12. J. R. Triplett, E. T. Merrilz and J. R. Burr. The RBU Reactor-Burnup Code: Formulation and operating Procedures, HW-70049. Available from Clearinghouse for Federal Scientific and Technical Information, July 1961.

D. H. Thomsen. Reactor Physics Monte Carlo Applications, BNWL-SA-1513. Battelle-Northwest, Richland, Washington, September 1967.

13. H. C. Honeck. ENDF/B, Specifications for an Evaluated Nuclear Data File for Reactor Applications, BNL-50066 (T-467), ENDF 102. Brookhaven National Laboratory, Upton, New York, May 1966. (revised July, 1967) (ENDF/B corrected to July 1, 1968).

14. D. C. Irving, R. G. Alsmizler, Jr., and H. S. Moran. Tissue Current-to-Dose Conversion Factors for Neutrons from 0.5 to $60 \mathrm{MeV}, 0 R N L-4032$. Oak Ridge National Laboratory, August 1967.

15. W. W. Engle, Jr. A User's Manual for ANISN, A One Dimensional Discrete Ordinates Transport Code with an Isotropic Scattering, K-1693. Union Carbide Corporation, Nuclear Division, Oak Ridge, Tennessee, March 1967.

16. R. G. Fairchizd. Sources of Fission Neutrons and Their Dosimetry, BNL-12452, Brookhaven National Laboratory, Upton, New York, May 1968.

17. J.A. Auxier, W. S. Snyder, and T. D. Jones. "Neutron Interactions and Penetration in Tissue," Radiation Dosimetry. Academic Press, New York and London, 1968. Vol. I. Ch. 6.

18. T. A. Barr and G. S. Hurst. "Fast Neutron Dose in a Large Tissue-Equivalent Phantom," Nucleonics, vol. 12 , no. 8, p. 33. 1954 .

19. G. O. Oliver, Jr. Fast Neutron Dosimetry of Californium252. University of Oklahoma, Norman, Oklahoma, 1968. (Ph. D. thesis)

20. G. D. OZiver Jr., and C. N. Wright. "Dosimetry of an Implantable 252 Cf Source," Radiology, vol. 92, p. 143. 1969.

21. G. S. Hurst. "An Absolute Tissue Dosimeter for Fast Neutrons," Brit. J. Radiol. vol. 27, p. 353. 
BNWL - 1489

22. H. H. Rossi. "Specification of Radiation Quality," Radiation Res., vol. 10, pp. 522-531. 1959.

23. W. A. Glass. "Apparatus of Local Energy Density Measurements," Pacific Northwest Laboratory Annual Report for 1965 in the Physical Sciences, BNWL-235-2, pp. 21-25. Battelle-Northwest, Richland, Washington, 1965.

24. G. W. R. Endres, W. A. Glass and A. J. Haverfield. "A Tissue Equivalent Proportional Counter for Measuring Doses Due to Neutron Radiation," Pacific Northwest Laboratory Annual Report Dosimetry Technology Studies, 1968 , BNWL-1159, pp. 7-30. Battelle-Northwest, Richland, Washington, 1969 . 
ᄂ . 


\section{DISTRIBUTION}

No. of

Copies

\section{OFFSITE}

1

AEC Chicago Patent Group

G. H. Lee

267

AEC Division of Technical Information Extension

\section{ONSITE-HANFORD}

1

AEC Chicago Patent Group

R. K. Sharp (Richland)

1

AEC Richland Operations Office

C. L. Robinson

Attn: B. A. Ryan

2

AEC RDT Assistant Director for Pacific Northwest Programs

T. A. Nemzek

7 Atlantic Richfield Hanford Company

S. J. Beard

A. E. Smith

H. H. Hopkins

G. C. Oberg

P. W. Smith

R. E. Tomlinson

M. J. Szulinski

3 Battelle Memorial Institute

3 Dona1d W. Douglas Laboratories

R. L. Andelin

$M$. Lewis

Files

3 Douglas United Nuclear

J. W. Riches

D. W. Peacock

W. K. Woods 
No. of

Copies

75

\section{Batte11e-Northwest}

E. L. Alpen

W. J. Bair

A. G. Blasewitz

L. W. Brackenbush

D. W. Brite

R. E. Burns

T. D. Chika11a

W. J. Clarke

F. T. Cross (15)

G. M. Dalen

D. R. de Halas

D. C. Deonigi

R. L. Dillon

J. C. Fox

H. T. Fullam

V. L. Hammond

J. E. Hansen (3)

A. J. Haverfield

J. H. Jarrett (3)

R. S. Kemper

C. E. Leach

R. W. McKee/E. T. Merrill

L. K. Mudge

J. M. Nielsen

R. E. Nightinga1e

H. M. Parker

R. W. Perkins

A. M. P1att

F. P. Roberts

C. A. Rohrmann

J. C. Sheppard

R. W. Stewart

R. C. Thompson

C. M. Unruh

U. L. Upson

W. Vali/R. L. Gordon

H. H. Van Tuy 1

J. B. Vetrano/D. R. Newman

E. E. Voiland

E. J. Wheelwright

N. A. Wogman

Technical Information Files

Technical Publications (2) 